\title{
Comparison of Antimicrobial Effect of Berberine as an Endodontic Irrigant with that of Other Common Root Canal Irrigants on Three Microorganisms Involved in Persistent Endodontic Infections
}

\author{
Zakiyeh Donyavi ${ }^{1}$, Mohammad Reza Arabestani², Dara Dastan ${ }^{3}$, Mohammad Esmaeilzadeh $^{4} \&$ \\ Nazanin Shahsavand ${ }^{5}$ \\ ${ }^{1}$ Assistant professor, Department of Endodontics, School of Dentistry, Hamadan University of Medical Sciences, \\ Hamadan, Iran \\ ${ }^{2}$ Associate professor, Department of microbiology, Hamadan University of Medical Sciences, Hamadan, Iran \\ ${ }^{3}$ Medicinal Plants and Natural Products Research Center, Hamadan University of Medical Sciences, Hamadan, \\ Iran \\ ${ }^{4}$ Assistant professor, Department of pediatric dentistry, School of Dentistry, Hamadan University of Medical \\ Sciences, Hamadan, Iran \\ ${ }^{5}$ Department of Endodontics, School of Dentistry, Hamadan University of Medical Sciences, Hamadan, Iran. \\ Correspondence: Nazanin Shahsavand, Department of Endodontics, School of Dentistry, Hamadan University of \\ Medical Sciences, Hamadan, Iran. Email: hamunidentist1@gmail.com
}

Received: July 15, 2017

Accepted: August 11, 2018

Online Published: October 15, 2018

doi:10.5539/jmbr.v8n1p153

URL: https://doi.org/10.5539/jmbr.v8n1p153

\begin{abstract}
Background and Aim: The present study investigated the antimicrobial effect of Berberine as an endodontic irrigant on the microorganisms involved in persistent endodontic infections. In this experimental in vitro trial, organisms Enterococcus Faecalis, Staphylococcus Aureus, and Staphylococcus Epidermidis were assessed in a multi-species biofilm tooth model.

Methods: Seventy-five single-rooted anterior teeth were collected and standardized to a length of $10 \mathrm{~mm}$. The teeth were randomly assigned into 5 groups. The teeth were then autoclaved to confirm being sterile. Afterwards, a biofilm consisting of the three selected bacteria was inoculated into the teeth and they were incubated for 21 days.

Results: The comparison of the amount of reduction in viable bacterial counts after irrigation by different solutions among the groups was done by Kruskal-wallis test while the changes of viable bacterial counts before and after irrigation with each solution was done by Wilocoxon Signed Ranks test. No significant difference existed among the studied irrigation solutions regarding the mean reduction of total viable bacterial counts, neither did it exist regarding the viable staphylococcus aureus, staphylococcus epidermidis or Enterococcus faecalis counts after irrigation. MIC of berberine against staphylococcus aureus, staphylococcus epidermidis and Enterococcus faecalis species were $0.5 \mu \mathrm{g} / \mathrm{ml}, 0.03 \mu \mathrm{g} / \mathrm{ml}$ and $1 \mu \mathrm{g} / \mathrm{ml}$, respectively. These values were found to be $0.39 \mu \mathrm{g} / \mathrm{ml}, 0.09 \mu \mathrm{g} / \mathrm{ml}$ and $0.78 \mu \mathrm{g} / \mathrm{ml}$ for $\mathrm{NaOCl}$ and $0.04 \mu \mathrm{g} / \mathrm{ml}, 0.04 \mu \mathrm{g} / \mathrm{ml}$ and $0.09 \mu \mathrm{g} / \mathrm{ml}$ for chlorhexidine, respectively.
\end{abstract}

Conclusion: it is concluded that Berberine can be used as a natural alternative instead of conventional root canal irrigants. However, more studies are required in order to confirm that characteristics of this substance are appropriate from other aspects.

\section{Introduction}

The effect of bacteria and their products has been proven as the major cause of development of pulpal and periapical diseases in many studies (Siqueira Jr, Rôças, \& Lopes, 2002). The main purpose of root canal treatment is to remove these microorganisms from root canal space and to achieve this, mechanical and chemical cleaning of the canal is essential (Tabrizizadeh, Zandi, Mehrjardi, \& Mahmodizadeh, 2014). However, certain microorganisms, including facultative gram-positive bacteria and certain types of fungi, may survive even after precise chemomechanical preparation of the root canal system and cause persistent root canal infections (Nabavizadeh et al., 2014).

Biofilm is a complex microbial community that is composed of a variety of bacteria that have different ecological needs and pathological potential. Biofilm not only effectively protects bacteria against host defense, but also resists 
them against a number of disinfectants that are used as oral hygiene products or drugs in the treatment of infections (Pinheiro et al., 2004).

The successful treatment of these resistant infections depends on biofilm removal and the effective killing of bacteria in biofilms (Pinheiro et al., 2004).

Enterococcus faecalis is a resistant microorganism that plays an essential role in persistent radical pericardial lesions after root canal treatment. It has also been found in $24 \%$ to $77 \%$ of endodontically treated teeth with apical periodontitis, as a single organism or as part of bacterial flora (Nosrat et al., 2009).

Removal of this bacterium by root canal therapy is very difficult because the bacterium penetrates into the dentinal tubules and stabilizes. Its ability to form biofilms and tolerate adverse environmental conditions explains its relatively high prevalence. Therefore, using a root canal irrigant that is effective on these bacteria can help to prevent refractory endodontic infections (Imanshahidi \& Hosseinzadeh, 2008; Sundqvist, Figdor, Persson, \& Sjögren, 1998). Staphylococci are also commonly found in persistent endodontic infections (Endo \& Dias Filho, 2015; Wei, Xu, \& Wu, 2011).

Root canal mechanical preparation is the initial procedure for cleansing the canal and irrigants are an essential complement to the treatment (Shuping, Ørstavik, Sigurdsson, \& Trope, 2000). Selection of a proper irrigating solution is important because of their different functions in removing debris, smear layer and bacteria from the root canal system. Different formulations of detergents have different functions on the pulp, necrotic tissues and microorganisms (Baumgartner, Hutter, \& Siqueira, 2006). Among these materials, sodium hypochlorite has been widely used as a successful irrigating solution after its introduction by Walker. Almost all studies have indicated its beneficial antimicrobial effects. Although this solution is used as a cleansing agent for the treatment of necrotic teeth due to its antimicrobial activity and its unique properties in tissue solubility, but it is toxic to vital tissues and its extrusion from apex causes pain and emphysema. On the other hand, it is csn induced allergic reactions and its taste is unfavorable for patients and its vapor is an eye stimulus (Baumgartner, Hutter, \& Siqueira, 2006; Leonardo et al., 2002; Ceri et al., 1999). Therefore, the study is still underway to find a solution with desirable antimicrobial properties and less side effects.

Chlorhexidine gluconate (CHX) is another detergent that has a wide antimicrobial spectrum as well as good substantivity by binding to hydroxyapatite as a final cleanser (Rôças, Siqueira Jr, \& Santos, 2004).

Due to the continuous increase in antibiotic-resistant strains due to the inappropriate use of antibiotics and the effects of synthetic detergents, researchers have recently started research into plant alternatives. Herbal detergents are harmless and non-toxic and have shown potent antibacterial effects in vitro (Leonardo et al., 2002). The antibacterial effects of green tea and Triphala, Monrinda Citrifolia, Zataria Multiflora Boiss, Satureja Jamzad Khuzistanica, Carvacol and Arctium Lappa have been studied as a detergent or intracanal drug in infectious root canals (Baumgartner, Hutter, \& Siqueira, 2006; Leonardo et al., 2002; Ceri et al., 1999; Rôças, Siqueira Jr, \& Santos, 2004).

Berberine, a quaternary ammonium salt of the isoquinolones group is found in plants such as Berberis Vulgaris, Goldenseal and Coptis Chinesis (Clauditz, Resch, Wieland, Peschel, \& Götz, 2006). Berberis Vugaris (Barberry) is well known in Iran, and various parts of this plant such as root, leaf and fruit juices are used as traditional drugs (Siqueira Jr \& Lima, 2002).

The mechanical treatment of the root canal is the initial method of cleansing the canal and washing solutions are an essential supplement to the treatment. Endodontic antimicrobial agents should be compatible with periapical tissues, in addition to being effective on pathogens. However, there are some disadvantages of some common irrigants, including their cytotoxicity, and adverse tissue effects in case of unintentional outflow from the canal. Therefore, there has recently been a growing trend towards the use of natural products in endodontic treatments (Nabavizadeh et al., 2014). Berberine has been studied in several studies because of its antimicrobial properties and biocompatubility, in order to determine its antibacterial and antifungal effects and its ability to be used as a root canal cleanser.

Considering the fact that in many studies, the most prevalent bacteria in persistent endodontic infections is Enterococcus faecalis and to a lesser extent are Staphylococcus aureus and Staphylococcus epidermidis, the aim of this study was to investigate the effect of Berberine as a natural root canal irrigants on these microorganisms.

\section{Materials and Method}

In this experimental in vitro trial, organisms Enterococcus Faecalis, Staphylococcus Aureus, and Staphylococcus Epidermidis were assessed in a multi-species biofilm tooth model. Seventy-five single-rooted anterior teeth were collected. The canals were prepared by crown-down technique by ProTaper rotary files using normal saline as an irrigant during cleaning and shaping procedures. Smear layer removal was done by 1 minute application of $17 \%$ EDTA $(10 \mathrm{~mL})$ and $5.25 \% \mathrm{NaOCl}(5 \mathrm{~mL})$. The roots were cut to standardized $10 \mathrm{~mm}$ sections and the root apices 
were sealed using cyanoacrylate glue in order to prevent apical leakage and the outer surfaces of the teeth were covered with a layer of nail laquer. The teeth were randomly assigned into 5 groups: Berberine $(2 \mathrm{mg} / \mathrm{mL}), 5.25 \%$ $\mathrm{NaOCl}$, Chlorhexidine gluconate $2 \%$, mixture of Berberine $1 \mathrm{mg} / \mathrm{ml}+$ Chlorhexidine gluconate $2 \%$ and Normal saline (control group). The teeth were then autoclaved to confirm being sterile. Afterwards, a biofilm consisting of the three selected bacteria (Enterococcus faecalis, Staphylococcus aureus and Staphylococcus epidermidis) was inoculated into the teeth and they were incubated for 21 days. After incubation, the root canals were irrigated 3 times with $10 \mathrm{ml}$ of normal saline and dried with strile \#40 paper points. In order to take initial samples, dentin chips were collected by using $\# 40$ hedstrom files and added to microtubes containing $1 \mathrm{ml}$ normal saline and $1 \%$ tween 80 and shaked for 30 seconds so that the microorganisms were separated. They were then cultured on Blood Agar medium and viable microorganisms were counted (S1). After that, the canals were flooded with irrigants for 5 minutes. They were then dried with \#40 paper point and each irrigant was neutralized by $5 \mathrm{ml}$ of the appropriate solution so as to prevent the carry-over effect. The neutralizer was dried with sterile paper point after 1 minute and sampling was performed as done before and the microorganisms were cultured on Blood Agar medium. The blood Agar media were incubated at $35^{\circ} \mathrm{C}$ for 48 hours and the viable bacteria were counted (S2). Ultimately, the S1 and $\mathrm{S} 2$ counts were compared. The comparison of the amount of reduction in viable bacterial counts after irrigation by different solutions among the groups was done by Kruskal-wallis test while the changes of viable bacterial counts before and after irrigation with each solution was done by Wilocoxon Signed Ranks test.

\section{Results}

No significant difference existed among the studied irrigation solutions regarding the mean reduction of total viable bacterial counts, neither did it exist regarding the reduction of viable staphylococcus aureus, staphylococcus epidermidis or Enterococcus faecalis counts after irrigation.

However, the effect size for $\mathrm{BBR}, \mathrm{NaOCl}, \mathrm{CHX}, \mathrm{BBR}+\mathrm{CHX}$ and saline was respectively:

$0.43,0.62,0.62,0.42$ and 0.3 against Enterococcus faecalis

$0.51,0.59,0.62,0.55$ and 0.52 against Staphylococcus aureus

$0.54,0.62,0.6,0.61$ and 0.4 against Staphylococcus epidermidis

and $0.55,0.62,0.62,0.62,0.55$ and 0.48 against the total biofilm bacteria.

MIC values against staphylococcus aureus, staphylococcus epidermidis and Enterococcus faecalis species were:

$0.5 \mu \mathrm{g} / \mathrm{ml}, 0.03 \mu \mathrm{g} / \mathrm{ml}$ and $1 \mu \mathrm{g} / \mathrm{ml}$ for BBR

$0.39 \mu \mathrm{g} / \mathrm{ml}, 0.09 \mu \mathrm{g} / \mathrm{ml}$ and $0.78 \mu \mathrm{g} / \mathrm{ml}$ for $\mathrm{NaOCl}$

And $0.04 \mu \mathrm{g} / \mathrm{ml}, 0.04 \mu \mathrm{g} / \mathrm{ml}$ and $0.09 \mu \mathrm{g} / \mathrm{ml}$ for chlorhexidine, respectively.

Table 1. MBC, MIC and inhibition zone diameter in the use of different irrigants against bacterial species

\begin{tabular}{|c|c|c|c|c|}
\hline $\begin{array}{l}\text { Halo of lack of } \\
\text { growth }\end{array}$ & MIC & $\mathrm{MBC}$ & group & Bacteria \\
\hline $\mathrm{mm} 11$ & $\mu \mathrm{g} / \mathrm{ml} / 5 / 0$ & $\mu \mathrm{g} / \mathrm{mll}$ & \multirow{4}{*}{$\begin{array}{l}\text { Berberine } \\
\mathrm{CHX} 2.0 \% \\
\mathrm{NaOCl} 5.25 \% \\
\mathrm{CHX}+\text { Berberin } \\
\mathrm{e}\end{array}$} & \multirow{5}{*}{ S. aureus } \\
\hline $\mathrm{mm} 30$ & $\mu \mathrm{g} / \mathrm{ml} 04 / 0$ & $\mu \mathrm{g} / \mathrm{ml} 09 / 0$ & & \\
\hline $\mathrm{mm} 40$ & $\mu \mathrm{g} / \mathrm{ml} 39 / 0$ & $\mu \mathrm{g} / \mathrm{ml} 78 / 0$ & & \\
\hline $\mathrm{mm} 28$ & $\mu \mathrm{g} / \mathrm{ml} 04 / 0$ & $\mu \mathrm{g} / \mathrm{ml} 09 / 0$ & & \\
\hline $\mathrm{mm} 19$ & & & Vancomycin & \\
\hline $\mathrm{mm} 38$ & $\mu \mathrm{g} / \mathrm{ml} 03 / 0$ & $\mu \mathrm{g} / \mathrm{ml} 106 / 0$ & Berberine & \multirow{5}{*}{$\begin{array}{l}\text { S. } \\
\text { epidermidis }\end{array}$} \\
\hline $\mathrm{mm} 45$ & $\mu \mathrm{g} / \mathrm{ml} 04 / 0$ & $\mu \mathrm{g} / \mathrm{ml} 09 / 0$ & CHX $2.0 \%$ & \\
\hline $\mathrm{mm} 41$ & $\mu \mathrm{g} / \mathrm{ml} 09 / 0$ & $\mu \mathrm{g} / \mathrm{ml} 19 / 0$ & $\mathrm{NaOCl} 5.25 \%$ & \\
\hline $\mathrm{mm} 38$ & $\mu \mathrm{g} / \mathrm{ml} 04 / 0$ & $\mu \mathrm{g} / \mathrm{ml} 09 / 0$ & $\begin{array}{l}\mathrm{CHX}+\text { Berberin } \\
\mathrm{e}\end{array}$ & \\
\hline $\mathrm{mm} 20$ & & & Vancomycin & \\
\hline Effectless & $\mu \mathrm{g} / \mathrm{ml} 1$ & $\mu \mathrm{g} / \mathrm{ml} 2$ & Berberine & \multirow{5}{*}{ E. faecalis } \\
\hline $\mathrm{mm} 21$ & $\mu \mathrm{g} / \mathrm{ml} 09 / 0$ & $\mu \mathrm{g} / \mathrm{ml} 19 / 0$ & CHX $2.0 \%$ & \\
\hline $\mathrm{mm} 29$ & $\mu \mathrm{g} / \mathrm{ml} 78 / 0$ & $\mu \mathrm{g} / \mathrm{ml} 56 / 1$ & $\mathrm{NaOCl} 5.25 \%$ & \\
\hline $\mathrm{mm} 20$ & $\mu \mathrm{g} / \mathrm{ml} 09 / 0$ & $\mu \mathrm{g} / \mathrm{ml} 19 / 0$ & CHX+Berberin & \\
\hline $\mathrm{mm} 20$ & & & Vancomycin & \\
\hline
\end{tabular}

\section{Discussion}

According to the results of the study conducted by Xie et al, Berberine alone and in combination with chlorhexidine reduced the number of live bacteria in the form of a laboratory protocol based on a study on a multibacterial biofilm (including Fusobacterium nucleatum, Enterococcus faecalis and Prevotella intermedia) (Xie, Johnson, Wenckus, 
Fayad, \& Wu, 2012). In the recent study, Berberine was found to be less effective in terms of using alone $(2 \mathrm{mg} / \mathrm{mL})$ than other cleansing solutions, but in combination with chlorhexidine $0.1 \%$, Berberine $(1 \mathrm{mg} / \mathrm{mL})$ demonstrated bactericidal comparable to sodium hypochlorite $5.25 \%$, chlorhexidine $2 \%$ and mixture of Berberine $1 \mathrm{mg} / \mathrm{ml}$ and chlorhexidine $1 \%$. Due to the use of Berberine at concentrations of $2 \mathrm{mg} / \mathrm{mL}$, as well as the combination of 1 $\mathrm{mg} / \mathrm{ml}$ Berberine and $1 \%$ chlorhexidine in the recent study and its antimicrobial effects, in our study we use the same concentrations. It should be noted that due to the difference in biofilm-forming bacteria in the research mentioned and the current study, unequality in the significance of differences between groups in two studies is justified. On the other hand, considering the size of the effects calculated in the present study, it is observed that the results of the present study are consistent with and confirm the recent study.

Iwazaki et al investigated antifungal activity of berberine and its synergism with fluconazole. According to recent research results, Berberine has a weak antifungal activity against Candida albicans in a concentration of $500 \mu \mathrm{g}$, but its combination with fluconazole showed strong antifungal activity (Iwazaki et al., 2010). Berberine, at concentrations greater than $0.9 \mu \mathrm{g} \mathrm{ml}$ and in combination with fluconazole, also had higher MIC values (greater than $1.09 \mu \mathrm{g} / \mathrm{ml}$ ) and resulted in the removal of residual turbidity in the incubation wells. In another study, Wei et al investigated antifungal activity of Berberine when used alone or in combination with antifungal azoles against planktonic and biofilm Candida using agar spreading and micro-dilution methods and results revealed that Berberine inhibited growth of different candidate species (9). In the recent study, the effects of synergy between Berberine and miconazole or fluconazole were reported in a disk diffusion method and in suspension, while neither berberine nor miconazole alone had the effects of inhibition on the formation of Candida albicans biofilm.

Yu et al confirmed synergistic effects between BBR and oxacillin against Staphylococcus aureus. Also, Wang et al reported the effects of BBR on biofilm of Staphylococcus epidermidis. On the other hand, Lee et al examined the antimicrobial effects of Berberine against oral bacteria associated with endodontic infections, and showed that Berberine had antimicrobial effects against A. actinomycetemcomitans and Enterococcus faecalis (Lee et al., 2013). According to the results of our study, BBR has the ability to eradicate Staphylococcus aureus and Staphylococcus epidermidis and Enterococcus faecalis the same as other irrigants such as $\mathrm{NaOCl}$, so these results were consistent with the results of the present study.

In a study by Xie et al BBR alone and in combination with chlorhexidine reduced the number of live bacteria in the form of an experimental protocol studying a multibacterial biofilm (including Fusobacterium nucleatum, Enterococcus faecalis and Prevotella intermedia).

In the recent study, BBR was found to be less effective when applied alone $(2 \mathrm{mg} / \mathrm{mL})$ than other irrigants, but when combined with chlorhexidine $1 \%$, BBR $(1 \mathrm{mg} / \mathrm{mL})$ exerted bactericidal results comparable to that of sodium hypochlorite $5.25 \%$, CHX $2 \%$ and $\mathrm{CHX} 1 \%$. It should be noted that due to differences in biofilm-producing bacteria of the research mentioned with the present study, the inequality of the significance of differences among the groups in two studies is justifiable. On the other hand, considering the size of the effects calculated in the present study, it is observed that the results of the present study are consistent with and confirm the recent study.

According to the results of the current study, sodium hypochlorite has the ability to destroy Staphylococcus aureus, Staphylococcus epidermidis and Enterococcus faecalis as other rinse solutions.

\section{Conclusion}

No significant difference existed among the studied irrigants regarding the mean reduction of total viable bacterial counts, neither did it exist regarding the reduction in viable staphylococcus aureus, staphylococcus epidermidis or Enterococcus faecalis counts after irrigation.

However, in all solutions (except in the normal saline group for Enterococcus faecalis species), the number of total viable bacterial counts and the number of viable bacterial counts of staphylococcus aureus, staphylococcus epidermidis and Enterococcus faecalis species decreased significantly after irrigation compared to the counts before irrigation.

MIC of Berberine against staphylococcus aureus, staphylococcus epidermidis and Enterococcus faecalis species were $0.5 \mu \mathrm{g} / \mathrm{ml}, 0.03 \mu \mathrm{g} / \mathrm{ml}$ and $1 \mu \mathrm{g} / \mathrm{ml}$, respectively. These values were found to be $0.39 \mu \mathrm{g} / \mathrm{ml}, 0.09 \mu \mathrm{g} / \mathrm{ml}$ and $0.78 \mu \mathrm{g} / \mathrm{ml}$ for $\mathrm{NaOCl}$ and $0.04 \mu \mathrm{g} / \mathrm{ml}, 0.04 \mu \mathrm{g} / \mathrm{ml}$ and $0.09 \mu \mathrm{g} / \mathrm{ml}$ for chlorhexidine, respectively.

Altogether, since the effective concentrations of berberine are achievable in vitro, and because of the similar antibacterial efficacy of berberine compared to that of other conventional irrigants, and considering it's natural and herbal essence and the fact that this substance is biocompatible and not cytotoxic (in contrary to some conventional irrigants which can cause adverse effects if unintentionally extruded beyond the canal space), it is concluded that Berberine can be used as a natural alternative instead of conventional root canal irrigants. However, more studies are required in order to confirm that characteristics of this substance are appropriate from other aspects. 


\section{References}

Baumgartner, J. C., Hutter, J. W., \& Siqueira, J. F. (2006). Endodontic microbiology and treatment of infections. Pathways of the Pulp, 2, 580-607.

Ceri, H., Olson, M. E., Stremick, C., Read, R. R., Morck, D., \& Buret, A. (1999). The Calgary Biofilm Device: new technology for rapid determination of antibiotic susceptibilities of bacterial biofilms. Journal of Clinical Microbiology, 37(6), 1771-1776.

Clauditz, A., Resch, A., Wieland, K. P., Peschel, A., \& Götz, F. (2006). Staphyloxanthin plays a role in the fitness of Staphylococcus aureus and its ability to cope with oxidative stress. Infection and Immunity, 74(8), 49504953.

Endo, E. H., \& Dias Filho, B. P. (2015). Antibacterial activity of berberine against methicillin-resistant Staphylococcus Aureus planktonic and biofilm cells. Austin J Trop Med Hyg, 1(1), 1005.

Imanshahidi, M., \& Hosseinzadeh, H. (2008). Pharmacological and therapeutic effects of Berberis vulgaris and its active constituent, berberine. Phytotherapy research, 22(8), 999-1012.

Iwazaki, R. S., Endo, E. H., Ueda-Nakamura, T., Nakamura, C. V., Garcia, L. B., \& Dias Filho, B. P. (2010). In vitro antifungal activity of the berberine and its synergism with fluconazole. Antonie Van Leeuwenhoek, 97(2), 201.

Lee, D., Kim, M. J., Park, S. N., Lim, Y. K., Min, J. B., Hwang, H. K., \& Kook, J. K. (2013). Antimicrobial activity of berberine against oral bacteria related to endodontic infections. International Journal of Oral Biology, 38(4), 141-147.

Leonardo, M. R., Silveira, F. F., Silva, L. A. B. D., Tanomaru Filho, M., \& Utrilla, L. S. (2002). Calcium hydroxide root canal dressing. Histopathological evaluation of periapical repair at different time periods. Brazilian Dental Journal, 17-22.

Nabavizadeh, M., Abbaszadegan, A., Gholami, A., Sheikhiani, R., Shokouhi, M., Shams, M. S., \& Ghasemi, Y. (2014). Chemical constituent and antimicrobial effect of essential oil from Myrtus communis leaves on microorganisms involved in persistent endodontic infection compared to two common endodontic irrigants: An in vitro study. Journal of conservative dentistry: $J C D, 17(5), 449$.

Nosrat, A., Bolhari, B., Sharifian, M. R., Aligholi, M., \& Mortazavi, M. S. (2009). The effect of Carvacrol on Enterococcus faecalis as a final irrigant. Iranian endodontic journal, 4(3), 96.

Pinheiro, E. T., Gomes, B. P. F. A., Drucker, D. B., Zaia, A. A., Ferraz, C. C. R., \& Souza-Filho, F. J. (2004). Antimicrobial susceptibility of Enterococcus faecalis isolated from canals of root filled teeth with periapical lesions. International endodontic journal, 37(11), 756-763.

Rôças, I. N., Siqueira Jr, J. F., \& Santos, K. R. (2004). Association of Enterococcus faecalis with different forms of periradicular diseases. Journal of Endodontics, 30(5), 315-320.

Shuping, G. B., Ørstavik, D., Sigurdsson, A., \& Trope, M. (2000). Reduction of intracanal bacteria using nickeltitanium rotary instrumentation and various medications. Journal of endodontics, 26(12), 751-755.

Siqueira Jr, J. F., \& Lima, K. C. (2002). Staphylococcus epidermidis and Staphylococcus xylosus in a secondary root canal infection with persistent symptoms: a case report. Australian Endodontic Journal, 28(2), 61-63.

Siqueira Jr, J. F., Rôças, I. N., \& Lopes, H. P. (2002). Patterns of microbial colonization in primary root canal infections. Oral Surgery, Oral Medicine, Oral Pathology, Oral Radiology, and Endodontology, 93(2), 174178.

Sundqvist, G., Figdor, D., Persson, S., \& Sjögren, U. (1998). Microbiologic analysis of teeth with failed endodontic treatment and the outcome of conservative re-treatment. Oral Surgery, Oral Medicine, Oral Pathology, Oral Radiology, and Endodontology, 85(1), 86-93.

Tabrizizadeh, M., Zandi, H., Mehrjardi, M. M., \& Mahmodizadeh, H. (2014). Comparing the Antibacterial Effect of Peganum Harmala Extract and 5/25\% Sodium Hypochlorite on Enterococcus Faeclis Biofilm. Journal of Shahid Sadoughi University of Medical Sciences, 22(3), 1256-1264.

Wei, G. X., Xu, X., \& Wu, C. D. (2011). In vitro synergism between berberine and miconazole against planktonic and biofilm Candida cultures. Archives of oral biology, 56(6), 565-572.

Xie, Q., Johnson, B. R., Wenckus, C. S., Fayad, M. I., \& Wu, C. D. (2012). Efficacy of berberine, an antimicrobial plant alkaloid, as an endodontic irrigant against a mixed-culture biofilm in an in vitro tooth model. Journal of Endodontics, 38(8), 1114-1117. 


\section{Copyrights}

Copyright for this article is retained by the author(s), with first publication rights granted to the journal.

This is an open-access article distributed under the terms and conditions of the Creative Commons Attribution license (http://creativecommons.org/licenses/by/4.0/). 